\title{
Impact of blood pressure levels within first 24 hours after mechanical thrombectomy on clinical outcome in acute ischemic stroke patients
}

\author{
David Cernik, ${ }^{1}$ Daniel Sanak, ${ }^{\oplus}$ Petra Divisova, ${ }^{2}$ Martin Kocher, ${ }^{3}$ Filip Cihlar, ${ }^{4}$ \\ Jana Zapletalova, ${ }^{5}$ Tomas Veverka, ${ }^{2}$ Andrea Prcuchova, ${ }^{1}$ Dusan Ospalik, ${ }^{1}$ Marie Cerna, ${ }^{3}$ \\ Petra Janousova, ${ }^{2}$ Michal Kral, ${ }^{2}$ Tomas Dornak, $^{2}$ Vojtech Prasil, ${ }^{3}$ David Franc, ${ }^{2}$ \\ Petr Kanovsky²
}

${ }^{1}$ Department of Neurology,

Krajska zdravotni as Masarykova nemocnice v Usti nad Labem oz, Usti nad Labem, Czech Republic ${ }^{2}$ Department of Neurology, Univ Hosp Olomouc, Olomouc, Czech Republic

${ }^{3}$ Department of Radiology, Univ Hosp Olomouc, Olomouc, Czech Republic

${ }^{4}$ Department of Radiology, Krajska zdravotni as Masarykova nemocnice $v$ Usti nad Labem $0 z$, Usti nad Labem, Czech Republic ${ }^{5}$ Department of Biometry and Statistics, Palacký University Medical School, Olomouc, Czech Republic

\section{Correspondence to} Dr Daniel Sanak, Department of Neurology, Univ Hosp Olomouc, Olomouc 779 00, Czech Republic; daniel.sanak@ centrum.cz

Received 8 November 2018 Revised 12 December 2018 Accepted 17 December 2018 Published Online First 6 February 2019
ABSTRACT

Introduction Despite early management and technical success of mechanical thrombectomy (MT) for acute ischemic stroke (AIS), not all patients reach a good clinical outcome. Different factors may have an impact and we aimed to evaluate blood pressure (BP) levels in the first 24 hours after MT.

Methods Consecutive AIS patients treated with MT were enrolled in the retrospective bi-center study. Neurological deficit was assessed with National Institutes of Health Stroke Scale (NIHSS) and functional outcome after 3 months with modified Rankin scale (mRS) with a score 0-2 for good outcome. The presence of symptomatic intracerebral hemorrhage $(\mathrm{SICH})$ was assessed according to the SITS-MOST criteria.

Results Of 703 treated patients, completed BP levels were collected in 690 patients (350 males, mean age $71 \pm 13$ years) with median of admission NIHSS 17 points. Patients with mRS 0-2 had a lower median of systolic BP (SBP) compared with those with poor outcome (131 vs $140 \mathrm{~mm} \mathrm{Hg}, \mathrm{P}<0.0001$ ). The rate of $\mathrm{SICH}$ did not differ between the patients with a median of SBP $<140 \mathrm{~mm} \mathrm{Hg}$ and $\geq 140 \mathrm{~mm} \mathrm{Hg}$. (5.1\% vs $5.1 \%, P=0.980)$. Multivariate regression analysis with adjustment for potential confounders showed a median of distolic BP ( $P=0.024$, OR: $0.977,95 \%$ Cl: 0.957 to $0.997)$ as a predictor of good functional outcome after MT, and a median of maximal SBP ( $P=0.038 ; 0 R$ : 0.990, $95 \% \mathrm{Cl}: 0.981$ to 0.999$)$ in the patients with achieved recanalization.

Conclusion Lowering of BP within the first 24 hours after MT may have a positive impact on clinical outcome in treated patients.

\section{INTRODUCTION}

Since the positive randomized trials and following the Highly Effective Reperfusion evaluated in Multiple Endovascular Stroke Trials (HERMES) meta-analysis showed a substantial clinical efficacy of mechanical thrombectomy (MT) in acute ischemic stroke (AIS), ${ }^{1}$ all centers performing MT worldwide are being challenged to achieve similar or better clinical results. Despite an experienced multidisciplinary stroke team, well organized hospital management, and good technical results, not all treated patients reach a good outcome.
Different factors may have an impact on functional outcome after $\mathrm{MT},{ }^{2-4}$ nevertheless, some cannot be affected and some have not yet been sufficiently established.

Although the levels of blood pressure (BP) are generally considered very important for recanalization therapy of AIS, only limited data about levels of BP before and after MT and its impact on clinical outcome are available up to date..$^{5-7}$ Moreover, the management of optimal BP in patients undergoing MT is not yet established, formal recommendations are missing, and most centers do not have a standardized protocol for post-MT BP treatment. ${ }^{8-11}$

The aim of our study was to evaluate the influence of BP values within the first 24 hours after MT on a 3 -month clinical outcome.

\section{METHODS}

All consecutive non-selected patients, who were treated with MT between 2010 and 2016 in both centers, were enrolled in this retrospective bi-center study. In all patients, the symptomatic occlusion of cerebral artery was detected on computed tomographic angiography or magnetic resonance angiography (MRA). MT was performed in case of occlusion of the middle cerebral artery (MCA; M1 or M2 segment), or distal part of internal carotid artery (ICA), or in the case of occlusion of basilar artery (BAO). In the case of arterial occlusion in anterior circulation, MT was initiated within the first 6 hours after stroke onset. In the case of BAO, MT was performed within the first 24 hours after stroke onset. The size of the hypodense area corresponding to acute infarction larger than one-third of MCA territory present on admission CT in the patients with IS in the anterior circulation was the only imaging exclusion criterion for MT. Prior severe disability and known fatal malignity were the clinical exclusion criteria. Patients with 'wake-up" strokes in the anterior circulation were treated with MT if no hypodense area corresponding to acute infarction was present on admission CT or no hypersignal area corresponding to acute infarction was present on admission MRI sequence fluid attenuation inversion recovery. Admission clinical status was evaluated using the National Institutes of Health Stroke scale 
Ischemic Stroke

Table 1 Patients' demographic and baseline clinical characteristics

\begin{tabular}{llccc}
\hline Parameter & All & mRS 0-2 & mRS 3-6 & P value \\
\hline N (males, \%) & $690(352,51 \%)$ & $332(176,53 \%)$ & $358(174,49 \%)$ & 0.247 \\
\hline Age (years, mean \pm SD) & $71 \pm 13$ & $67 \pm 13$ & $72 \pm 12$ & $<0.0001$ \\
\hline Admission NIHSS - median (range) & $17(1-42)$ & $15(1-36)$ & $18(1-42)$ & $<0.0001$ \\
\hline Hypertension $(n, \%)$ & $525(76 \%)$ & $229(69 \%)$ & $296(83 \%)$ & $<0.0001$ \\
\hline Diabetes mellitus $(n, \%)$ & $188(27 \%)$ & $71(21 \%)$ & $117(33 \%)$ & 0.001 \\
\hline Ischemic cardiopathy $(n, \%)$ & $191(28 \%)$ & $80(24 \%)$ & $111(31 \%)$ & 0.043 \\
\hline Hyperlipidemia $(n, \%)$ & $297(43 \%)$ & $140(42 \%)$ & $157(44 \%)$ & 0.655 \\
\hline Atrial fibrillation $(n, \%)$ & $299(43 \%)$ & $130(39 \%)$ & $168(47 \%)$ & 0.039 \\
\hline MCA occlusion $(n, \%)$ & $567(82 \%)$ & $285(86 \%)$ & $282(79 \%)$ & 0.015 \\
\hline ICA occlusion $(n, \%)$ & $160(23 \%)$ & $70(21 \%)$ & $90(25 \%)$ & 0.207 \\
\hline BA occlusion $(n, \%)$ & $84(12 \%)$ & $32(10 \%)$ & $52(15 \%)$ & 0.05 \\
\hline Prior IV thrombolysis $(n, \%)$ & $519(75 \%)$ & $272(82 \%)$ & $247(69 \%)$ & $<0.0001$ \\
\hline BA, basl $)$ &
\end{tabular}

BA, basilar artery; ICA, internal carotid artery; MCA, middle cerebral artery; mRS, modified Rankin Scale; NIHSS, National Institutes of Health Stroke Scale.

(NIHSS) by a certified neurologist. Intravenous thrombolysis (IVT) was administered within the first 4.5 hours from stroke onset prior to MT if indicated. In patients with BAO, IVT was performed within the first 24 hours from stroke onset. Mechanical thrombectomy was performed using stent retrievers (Solitaire, Catch Device, Trevo, and pRESET). Achieved recanalization status was assessed according to the Thrombolysis in Cerebral Infarction Scale (TICI) on the final angiogram. ${ }^{12}$

In all patients, the occurrence of intracerebral hemorrhage (ICH) was assessed on the control CT or MRI after 24 hours. Symptomatic ICH was defined as a local remote parenchymal hematoma (type 2) or subarachnoid hemorrhage associated with at least a 4-point increase in NIHSS score or leading to death. ${ }^{13}$ Neurological deficit was evaluated using the NIHSS after 24 hours and clinical outcome after 3 months using the modified Rankin scale (mRS). A score of $0-2$ points was considered a good outcome. The mRS scoring was performed by an experienced certified neurologist and mostly during scheduled outpatient visits. In some patients, the scoring was performed by phone call with patient's relatives or caregivers.

The patient's BP levels in the first 24 hours after MT were collected as 24 values of systolic BP (SBP) and diastolic BP (DBP) recorded each hour during hospitalization at the intensive care unit (ICU) after performed MT. The treatment of elevated BP and target BP levels depended on treating physician's decision and clinical status of an individual patient. In the case of previously performed IVT, the BP level $185 / 110 \mathrm{~mm} \mathrm{Hg}$ was respected as the maximal upper limit. ${ }^{14} 15$ IV administered urapidil (Ebrantil,
Takeda GmbH, Singen, Germany) was the first choice for the BP treatment in most patients in a form of repeated injections or infusion. For the analysis, patients were divided into two groups according to presence/absence of good outcome and compared in values of SBP and DBP. Subsequently, subgroups of patients with a median of SBP $<140 \mathrm{~mm} \mathrm{Hg}$ and $\geq 140 \mathrm{~mm} \mathrm{Hg}$ were analyzed.

The study protocol was in compliance with the Declaration of Helsinki (1975) and was approved by the ethical committee of our hospitals.

Statistical analysis SPSS software (version 22.0; SPSS, Chicago, IL) was used for the statistical analysis. Fisher's exact test and the Kruskal-Wallis test were used for nonparametric variables. Data normality was tested using the Shapiro-Wilk test. Univariable and multivariable logistic regression analysis were used to evaluate SBP and DBP as possible predictors of a good 3-month clinical outcome. A multivariate regression model was adjusted for the following potential confounders: age, arterial hypertension, diabetes mellitus, atrial fibrillation, admission NIHSS, IVT, admission glycemia, recanalization time (onset to maximal achieved recanalization time), and SICH. All tests used $\alpha$-level of 0.05 for significance.

\section{RESULTS}

In total, 703 patients were treated with MT using stent retrievers in both centers during the investigated period (2010-2016). Completed BP values within the first 24 hours after MT were collected in 690 patients (350 males, mean age $71 \pm 13$ years).

Table 2 Treatment results and their comparison between patients with median of SBP $<140 \mathrm{~mm} \mathrm{Hg}$ and $\geq 140 \mathrm{~mm}$ Hg within first $24 \mathrm{hours}$ after mechanical thrombectomy

\begin{tabular}{|c|c|c|c|c|}
\hline Parameter & All & SBP med $<140 \mathrm{~mm} \mathrm{Hg}$ & $\mathrm{SBP}$ med $\geq 140 \mathrm{~mm} \mathrm{Hg}$ & $P$ value \\
\hline Recanalization time (min, mean \pm SD) & $240 \pm 95$ & $240 \pm 80$ & $240 \pm 110$ & 0.271 \\
\hline Recanalization ( $\mathrm{TICl} \geq 2 \mathrm{~b}, \mathrm{n}, \%)$ & $551(79.9 \%)$ & $305(81.1 \%)$ & $246(78.3 \%)$ & 0.366 \\
\hline Complete recanalization ( $\mathrm{TICI} 3, \mathrm{n}, \%)$ & $444(64.3 \%)$ & $249(66.2 \%)$ & $195(62.1 \%)$ & 0.260 \\
\hline $\mathrm{ICH}(\mathrm{n}, \%)$ & $199(29 \%)$ & $103(27.4 \%)$ & $96(30.6 \%)$ & 0.359 \\
\hline SICH $(n, \%)$ & $35(5 \%)$ & $19(5.1 \%)$ & $16(5.1 \%)$ & 0.980 \\
\hline Median of $\mathrm{mRS}$ at 90 days & 3 & 2 & 4 & 0.0002 \\
\hline $\mathrm{mRS} \leq 2$ at 90 days $(\mathrm{n}, \%)$ & $332(48 \%)$ & $202(53.7 \%)$ & $130(41.4 \%)$ & 0.001 \\
\hline Mortality at 7 days $(n, \%)$ & $58(8 \%)$ & $29(7.7 \%)$ & $29(9.2 \%)$ & 0.473 \\
\hline Mortality at 90 days $(n, \%)$ & $189(27 \%)$ & $88(23.4 \%)$ & $101(32.2 \%)$ & 0.010 \\
\hline
\end{tabular}

$\mathrm{ICH}$, intracerebral hemorrhage; mRS, modified Rankin Scale, SICH, symptomatic intracerebral hemorrhage; TICl, Thrombolysis in Cerebral Infarction Scale. 
Table 3 Comparison of BP levels between patients with good and poor outcome in subgroups analysis according to achieved recanalization status

\begin{tabular}{|c|c|c|c|c|c|c|c|c|c|c|c|c|c|}
\hline \multirow{2}{*}{\multicolumn{2}{|c|}{ Patient group }} & \multicolumn{2}{|l|}{ All } & \multicolumn{3}{|c|}{$\mathrm{TICl} 3$} & \multirow[b]{2}{*}{$P$ value } & \multicolumn{2}{|l|}{$\mathrm{TICl} \geq 2 \mathrm{~b}$} & \multirow[b]{2}{*}{ P value } & \multicolumn{2}{|l|}{$\mathrm{TICl}<2 \mathrm{~b}$} & \multirow[b]{2}{*}{$P$ value } \\
\hline & & mRS 0-2 & mRS 3-6 & $P$ value & mRS 0-2 & mRS 3-6 & & mRS 0-2 & mRS 3-6 & & mRS 0-2 & mRS 3-6 & \\
\hline $\mathrm{N}$ & & 332 & 358 & & 249 & 195 & & 301 & 250 & & 31 & 108 & \\
\hline \multirow{4}{*}{$\begin{array}{l}\text { SBP } \\
(\mathrm{mm} \mathrm{Hg})\end{array}$} & Mean $\pm S D$ & $133 \pm 15$ & $139 \pm 16$ & $<0.0001$ & $132 \pm 15$ & $137 \pm 15$ & 0.0004 & $132 \pm 15$ & $138 \pm 15$ & $<0.0001$ & $135 \pm 14$ & $139 \pm 18$ & 0.138 \\
\hline & Median & 131 & 140 & & 130 & 139 & & 131 & 140 & & 135 & 140 & \\
\hline & 25 percentile & 120 & 128 & & 120 & 128 & & 120 & 128 & & 122 & 130 & \\
\hline & 75 percentile & 144 & 150 & & 143 & 150 & & 143 & 150 & & 148 & 152 & \\
\hline \multirow{4}{*}{$\begin{array}{l}\text { DBP } \\
(\mathrm{mm} \mathrm{Hg})\end{array}$} & Mean $\pm S D$ & $69 \pm 9$ & $70 \pm 10$ & 0.094 & $68 \pm 9$ & $69 \pm 9$ & 0.599 & $68 \pm 9$ & $69 \pm 10$ & 0.201 & $73 \pm 9$ & $71 \pm 10$ & 0.572 \\
\hline & Median & 70 & 70 & & 69 & 70 & & 69 & 70 & & 71 & 70 & \\
\hline & 25 percentile & 60 & 63 & & 60 & 62 & & 60 & 62 & & 67 & 64 & \\
\hline & 75 percentile & 75 & 76 & & 74 & 73 & & 74 & 75 & & 78 & 80 & \\
\hline \multirow{4}{*}{$\begin{array}{l}\text { Max.SBP } \\
(\mathrm{mm} \mathrm{Hg})\end{array}$} & Mean \pm SD & $161 \pm 22$ & $172 \pm 24$ & $<0.0001$ & $161 \pm 22$ & $171 \pm 23$ & $<0.0001$ & $161 \pm 22$ & $171 \pm 23$ & $<0.0001$ & $164 \pm 23$ & $174 \pm 25$ & 0.032 \\
\hline & Median & 160 & 170 & & 160 & 170 & & 160 & 170 & & 160 & 177 & \\
\hline & 25 percentile & 147 & 155 & & 145 & 155 & & 147 & 155 & & 147 & 160 & \\
\hline & 75 percentile & 175 & 188 & & 175 & 185 & & 175 & 185 & & 180 & 190 & \\
\hline \multirow{4}{*}{$\begin{array}{l}\text { Max.DBP } \\
(\mathrm{mm} \mathrm{Hg})\end{array}$} & Mean \pm SD & $90 \pm 15$ & $93 \pm 15$ & 0.002 & $89 \pm 13$ & $93 \pm 15$ & 0.015 & $90 \pm 14$ & $93 \pm 15$ & 0.008 & $95 \pm 22$ & $94 \pm 15$ & 0.628 \\
\hline & Median & 90 & 90 & & 90 & 90 & & 90 & 90 & & 90 & 90 & \\
\hline & 25 percentile & 80 & 85 & & 80 & 84 & & 80 & 82 & & 84 & 85 & \\
\hline & 75 percentile & 98 & 100 & & 96 & 100 & & 96 & 100 & & 100 & 101 & \\
\hline
\end{tabular}

DBP, diastolic blood pressure, Max., maximal recorded BP value within first 24 hours after mechanical thrombectomy; mRS, modified Rankin Scale; SBP, systolic blood pressure; TICl, Thrombolysis in Cerebral Infarction Scale.

Demographic and baseline characteristics of analyzed patients are shown in table 1.

The recanalization (TICI 2b-3) was reached in 551 (79.9\%) patients and complete recanalization (TICI 3) in 444 (64.3\%) patients. Good 90-day clinical outcome (mRS 0-2) was present in $331(48 \%)$ patients and $186(27 \%)$ patients died within 3 months. ICH after MT was observed in 200 (29\%) and SICH in 35 (5\%) patients (table 2).

Patients with good outcome had a significantly lower median of SBP and median of maximal recorded SBP compared with those with poor outcome (131 vs $140 \mathrm{~mm} \mathrm{Hg}, \mathrm{P}<0.0001 ; 160$ vs $170 \mathrm{~mm} \mathrm{Hg}, \mathrm{P}<0.0001$; table 3 ). Similarly, in the subgroup of patients with achieved recanalization (TICI 2b-3) and with complete recanalization (TICI 3): patients with good outcome had again lower median of SBP (131 vs $140 \mathrm{~mm} \mathrm{Hg}, \mathrm{P}<0.0001$; 130 vs $139 \mathrm{~mm} \mathrm{Hg}, \mathrm{P}=0.0004$, table 3). Patients with good outcome were also significantly younger and more frequently treated with IVT, had lower admission NIHSS, less frequently arterial hypertension, atrial fibrillation, and diabetes (table 1).

In the subgroup analysis, patients with a median of SBP $<140 \mathrm{~mm} \mathrm{Hg}$ had significantly better clinical outcome and lower 3-month mortality (table 2), whereas no significant difference was found in the recanalization times and rates between both analyzed subgroups. Similarly, the rate of ICH and SICH did not differ between the patients with a median of SBP $<140 \mathrm{~mm}$ $\mathrm{Hg}$ and $\geq 140 \mathrm{~mm} \mathrm{Hg}(27.4 \%$ vs $30.6 \%, \mathrm{P}=0.980)$ (table 2$)$. Patients with SICH had a similar median of SBP and DBP within the first 24 hours after MT compared with those without SICH (table 4).

Univariate logistic regression analysis showed median of SBP $(\mathrm{P}<0.0001$, OR: $0.976,95 \% \mathrm{CI}: 0.966$ to 0.0986$)$, median of maximal recorded SBP ( $\mathrm{P}<0.0001$, OR: $0.979,95 \%$ CI: 0.972 to 0.986), and DBP ( $\mathrm{P}=0.008$, OR: $0.986,95 \% \mathrm{CI}: 0.976$ to 0.996$)$ as independent predictors of good outcome after MT (table 5). Similar results were shown also in the subgroup of patients with achieved recanalisation (TICI 2b-3) and with complete recanalization (table 5). A multivariate regression model with adjustment for potential confounders showed a median of DBP ( $\mathrm{P}=0.024$, OR: $0.977,95 \% \mathrm{CI}: 0.957$ to 0.997$)$ as a predictor of a good 3-month clinical outcome only (table 6). In the subgroup analysis, a median of maximal recorded SBP $(\mathrm{P}=0.038$, OR: $0.990,95 \%$ CI: 0.981 to 0.999 ) was shown as a predictor in the patients with achieved recanalization (TICI 2b-3) and a median of maximal recorded DBP ( $\mathrm{P}=0.046$, OR: $0.984,95 \% \mathrm{CI}: 0.969$ to 1.000 ) in the patients with complete recanalization (table 6).

\section{DISCUSSION}

Results of our study showed that AIS patients with a good 3-month outcome after MT had significantly lower SBP values within the first 24 hours after recanalization intervention. Patients with a median of SBP $<140 \mathrm{~mm} \mathrm{Hg}$ had significantly better clinical outcome and a lower 3-month mortality. Post-treatment SBP and DBP were found as independent predictors of good outcome and our results support the previously reported data

\begin{tabular}{|c|c|c|c|}
\hline Parameter & SICH patients & Non-SICH patients & $P$ value \\
\hline $\mathrm{N}$ (males, \%) & $35(20,57)$ & $649(327,50)$ & 0.436 \\
\hline Age (years, mean $\pm S D$ ) & $72.0 \pm 8.7$ & $71.0 \pm 12.6$ & 0.264 \\
\hline Admission NIHSS (median, range) & $18(5-42)$ & $16(2-36)$ & 0.095 \\
\hline Prior IV thrombolysis (n, \%) & $24(68.6 \%)$ & $492(75.8 \%)$ & 0.333 \\
\hline SBP (median, range) & $130(100-164)$ & $135(60-180)$ & 0.813 \\
\hline DBP (median, range) & $69(46-86)$ & $70(40-102)$ & 0.590 \\
\hline Maximal SBP (median, range) & $175(135-230)$ & $165(130-250)$ & 0.029 \\
\hline Maximal DBP (median, range) & $90(72-118)$ & $90(56-198)$ & 0.862 \\
\hline
\end{tabular}

DB, diastolic blood pressure, ICA, internal carotid artery, IV, intravenous, MCA, middle cerebral artery; NIHSS, National Institutes of Health Stroke Scale; SBP, systolic blood pressure; SICH, symptomatic intracerebral hemorrhage. 
Table 5 Univariate logistic regression analysis for identification of independent predictors of a good 3-month clinical outcome: subgroup analysis of all patients, patients with achieved recanalization ( $\mathrm{TICl} 2 \mathrm{~b}-3$ ), and complete recanalization (TICl 3)

\begin{tabular}{|c|c|c|c|c|c|c|c|c|c|}
\hline \multirow{2}{*}{$\begin{array}{l}\text { Subgroup } \\
\text { Variable }\end{array}$} & \multicolumn{3}{|c|}{ All patients } & \multicolumn{3}{|c|}{$\mathrm{TICl} 2 \mathrm{~b}-3$ patients } & \multicolumn{3}{|c|}{ TICI 3 patients } \\
\hline & $P$ value & OR & $95 \% \mathrm{Cl}$ & $P$ value & OR & $95 \% \mathrm{Cl}$ & $P$ value & OR & $95 \% \mathrm{Cl}$ \\
\hline Age & $<0.0001$ & 0.968 & 0.956 to 0.981 & $<0.0001$ & 0.968 & 0.954 to 0.983 & 0.0004 & 0.971 & 0.955 to 0.987 \\
\hline NIHSS & $<0.0001$ & 0.897 & 0.873 to 0.921 & $<0.0001$ & 0.895 & 0.869 to 0.922 & $<0.0001$ & 0.892 & 0.864 to 0.921 \\
\hline Diabetes mellitus & 0.001 & 0.560 & 0.398 to 0.790 & 0.0004 & 0.511 & 0.352 to 0.741 & 0.0003 & 0.465 & 0.308 to 0.702 \\
\hline Hypertension & $<0.0001$ & 0.466 & 0.325 to 0.667 & 0.003 & 0.534 & 0.354 to 0.805 & 0.009 & 0.540 & 0.340 to 0.857 \\
\hline Atrial fibrillation & 0.040 & 0.728 & 0.538 to 0.985 & 0.113 & 0.761 & 0.542 to 1.067 & 0.183 & 0.774 & 0.530 to 1.129 \\
\hline IV thrombolysis & 0.0001 & 2.037 & 1.424 to 2.915 & 0.002 & 1.893 & 1.264 to 2.834 & 0.001 & 2.129 & 1.361 to 3.332 \\
\hline Recanalization time & $<0.0001$ & 0.995 & 0.993 to 0.997 & $<0.0001$ & 0.995 & 0.993 to 0.998 & 0.0001 & 0.995 & 0.993 to 0.998 \\
\hline $\mathrm{SICH}$ & 0.0005 & 0.028 & 0.004 to 0.208 & 0.0004 & 0.026 & 0.004 to 0.195 & 0.001 & 0.030 & 0.004 to 0.224 \\
\hline Median SBP & $<0.0001$ & 0.976 & 0.966 to 0.986 & $<0.0001$ & 0.975 & 0.964 to 0.986 & 0.0004 & 0.977 & 0.965 to 0.990 \\
\hline Median max. SBP & $<0.0001$ & 0.979 & 0.972 to 0.986 & $<0.0001$ & 0.979 & 0.971 to 0.987 & $<0.0001$ & 0.980 & 0.971 to 0.988 \\
\hline Median DBP & 0.097 & 0.987 & 0.971 to 1.002 & 0.195 & 0.988 & 0.970 to 1.006 & 0.815 & 0.998 & 0.977 to 1.018 \\
\hline Median max. SBP & 0.008 & 0.986 & 0.976 to 0.996 & 0.010 & 0.984 & 0.972 to 0.996 & 0.012 & 0.983 & 0.970 to 0.996 \\
\hline
\end{tabular}

$\mathrm{Cl}$, Cl interval, DBP, diastolic blood pressure, max., maximal, MT, mechanical thrombectomy, NIHSS, National Institutes of Health Stroke Scale, OR, odds ratio, SBP, systolic blood pressure, $\mathrm{SICH}$, symptomatic intracerebral hemorrhage, $\mathrm{TICl}$, Thrombolysis in Cerebral Infarction Scale

from recent studies. ${ }^{5-7}$ Furthermore, the associations between a higher admission SBP and a lower likelihood of 3-month favorable functional outcome and increased final infarction volume after MT were reported recently. ${ }^{16}$

Despite limited evidence on BP levels during and after MT, our findings may support an importance of BP levels in the management after MT. Clear and reliable recommendations for the management of BP in patients with AIS, who undergo MT, have not yet been established and most centers do not have a standardized protocol for BP treatment after $\mathrm{MT}^{8-11}$ Thus we suggest that our findings might contribute to a large discussion on optimal BP management after MT. A recent survey among US centers showed that the majority tended to lower BP levels in patients with successful recanalization and kept higher BP levels in those with unsuccessful recanalization. ${ }^{11}$

In the subgroup of our patients without achieved recanalisation (TICI <2b), no significant difference was found in SBP levels between those with good and poor outcome (table 3). These findings contradict a generally accepted paradigm that higher BP maintains collateral perfusion in the case of persistent cerebral arterial occlusion. Our results support a previously reported association between increased SBP and DBP levels in non-recanalized patients and a higher likelihood of 3-month mortality and poor outcome. ${ }^{6}$ We did not analyze patients with the recanalization grade of TICI $2 \mathrm{~b}$ and $2 \mathrm{c}$ individually, thus we were not able to evaluate whether patients with incomplete recanalization required really higher BP levels to maintain collateral perfusion. In addition, a multivariate regression model with adjustment for potential confounders showed a median of maximal SBP as a significant predictor of good outcome in the patients with achieved recanalization (TICI 2b-3), but not the median of SBP. Furthermore, in the patients with complete recanalization (TICI 3), the multivariate model did not show either SBP variable as a predictor of good outcome (table 6). This may be explained by a previously reported finding that variability of BP with higher maximal SBP peaks, supporting and maintaining collateral perfusion in patients with incomplete recanalization (TICI $2 b-c$ ), is strongly associated with poor outcome..$^{51718}$ It can be also speculated that the previously

Table 6 Significant predictors of a good 3-month clinical outcome in multivariate logistic regression model adjusted for age, admission NIHSS, arterial hypertension, diabetes mellitus, atrial fibrillation, pretreatment IVT, admission glycemia, recanalization time (onset to maximal achieved recanalization time), SICH, medians of SBP and DBP, and medians of maximal SBP and DBP. Subgroup analysis of all patients, patients with achieved recanalization ( $\mathrm{TICl} 2 \mathrm{~b}-3)$, and complete recanalization $(\mathrm{TICl} 3)$

\begin{tabular}{|c|c|c|c|c|c|c|c|c|c|}
\hline Subgroup & All patien & & & $\mathrm{TICl} 2 \mathrm{~b}-3$ & tients & & $\mathrm{TICl} 3$ pa & & \\
\hline Variable & $P$ value & OR & $95 \% \mathrm{Cl}$ & $P$ value & OR & $95 \% \mathrm{Cl}$ & $P$ value & $\mathrm{OR}$ & $95 \% \mathrm{Cl}$ \\
\hline Age & $<0.0001$ & 0.959 & 0.942 to 0.976 & 0.001 & 0.970 & 0.952 to 0.988 & 0.002 & 0.967 & 0.947 to 0.987 \\
\hline Admission NIHSS & $<0.0001$ & 0.898 & 0.870 to 0.927 & $<0.0001$ & 0.900 & 0.871 to 0.931 & $<0.0001$ & 0.891 & 0.859 to 0.925 \\
\hline Admission glycemia & 0.0001 & 0.839 & 0.767 to 0.918 & 0.001 & 0.861 & 0.785 to 0.944 & 0.0004 & 0.828 & 0.745 to 0.919 \\
\hline IV thrombolysis & 0.003 & 1.985 & 1.255 to 3.140 & 0.015 & 1.811 & 1.122 to 2.923 & 0.005 & 2.137 & 1.250 to 3.653 \\
\hline Recanalization time & $<0.0001$ & 0.995 & 0.993 to 0.997 & 0.0001 & 0.995 & 0.992 to 0.997 & 0.0001 & 0.994 & 0.991 to 0.997 \\
\hline $\mathrm{SICH}$ & 0.0005 & 0.055 & 0.007 to 0.425 & 0.010 & 0.066 & 0.008 to 0.522 & 0.004 & 0.049 & 0.006 to 0.385 \\
\hline Median max. SBP & NS & & & 0.038 & 0.990 & 0.981 to 0.999 & NS & & \\
\hline Median DBP & 0.024 & 0.977 & 0.957 to 0.997 & NS & & & NS & & \\
\hline Median max. DBP & NS & & & NS & & & 0.046 & 0.984 & 0.969 to 1.000 \\
\hline
\end{tabular}

DBP, diastolic blood pressure; IV, intravenous; MT, mechanical thrombectomy, max., maximal; NIHSS, National Institutes of Health Stroke Scale; NS, not significant;

SBP, systolic blood pressure; SICH, symptomatic intracerebral hemorrhage; TICI, Thrombolysis in Cerebral Infarction Scale. 
reported significant decline of SBP within the first 8-12 hours after successful recanalization might have some potential effect. ${ }^{19}$

In the patients with complete recanalization, the multivariate regression model showed the median of maximal DBP as a significant predictor for good outcome (table 6). We may hypothesize that elevated DBP does not principally support cerebral collateral perfusion, but it is more likely associated with pre-treatment diseases (poorly controlled arterial hypertension, diabetes mellitus, atrial fibrillation, ischemic cardiopathy, renal failure) that are common independent predictors for worse outcome after MT. ${ }^{20} 21$

No association between the occurrence of SICH and BP levels after MT was found and our finding supports the previous report of Goyal et al, ${ }^{5}$ but it contradicts the reported data of Mistry et al. ${ }^{7}$ In spite of this, we admit that the low number of our patients with SICH might affect our findings. It can be hypothesized that BP levels during intervention and immediately after the end of MT may be more important for the risk of SICH. ${ }^{5}$ IVT may also increase the risk of SICH, but the combination of MT with previous IVT did not increase the risk of SICH in our patients (table 4). Likewise in the positive randomized trials ${ }^{1}$ and the rate of SICH in our study (5\%) was similar to the reported from the HERMES meta-analysis (4.4\%). ${ }^{1}$

The presented study has limitations. A retrospective observational analysis was used in the presented study. BP values during the intervention were not collected, a BP value recorded at the patient's admission to ICU after performed MT was the first collected for our analysis. Nevertheless, a recent post-hoc analysis of the Sedation vs. Intubation for Endovascular Stroke Treatment trial showed no association between the difference in SBP, DBP, and mean arterial pressure from baseline to the different phases of thrombectomy intervention and NIHSS change after 24 hours. ${ }^{22}$ Moreover, no association was found between BP drops during intervention and a change in $\mathrm{mRS}$ at 3 months. ${ }^{22}$

Although most of our patients were treated for hypertension after MT with intravenously administered urapidil, some patients were treated also with other medicaments. Our study was focused on clinical outcomes specifically and no additional imaging analysis was performed to assess the possible relationship between infarct and penumbral volumes and BP levels.

In conclusion, our study demonstrates that patients with lower BP levels within the first 24 hours after MT may have better clinical outcome and lower 3-month mortality. In the absence of evidence from clinical trials, missing reliable recommendations, and different management of BP among endovascular centers worldwide, a further large multicenter prospective study is strongly warranted.

Contributors DC, DS: study concept and design, acquisition of data, analysis and interpretation of data; drafting and critical revision of the manuscript for important intellectual content; and final approval of the version to be published. PD: acquisition of data, analysis and interpretation of data; drafting and critical revision of the manuscript for important intellectual content. MK, FC: acquisition of data, critical revision of the manuscript for important intellectual content. JZ: statistical analysis, interpretation of analysis. TV, AP, DO, MC, PJ, MK: acquisition of data, critical revision of the manuscript for important intellectual content. TD: acquisition of data, analysis and interpretation of data, drafting and critical revision of the manuscript for important intellectual content. VP, DF: acquisition of data, critical revision of the manuscript for important intellectual content. PK: critical revision of the manuscript for important intellectual content.

Funding This study was funded by IGA LF UP (grant number: 018_2018); Ministerstvo Zdravotnictví Ceské Republiky (grant number: 17-30101A); Krajska Zdravotní, a.s. (grant number: IGA-KZ-2017-1-2).

Competing interests None declared.
Patient consent for publication Not required.

Provenance and peer review Not commissioned; externally peer reviewed.

\section{REFERENCES}

1 Goyal M, Menon BK, van Zwam WH, et al. Endovascular thrombectomy after large-vessel ischaemic stroke: a meta-analysis of individual patient data from five randomised trials. Lancet 2016:387:1723-31.

2 Linfante I, Starosciak AK, Walker GR, et al. Predictors of poor outcome despite recanalization: a multiple regression analysis of the NASA registry. J Neurointerv Surg 2016;8:224-9

3 Sallustio F, Motta C, Pizzuto S, et al. CT angiography-based collateral flow and time to reperfusion are strong predictors of outcome in endovascular treatment of patients with stroke. J Neurointerv Surg 2017;9:940-3.

4 Gordon WR, Salamo RM, Behera A, et al. Association of blood glucose and clinical outcome after mechanical thrombectomy for acute ischemic stroke. Interv Neurol 2018:7:182-8

5 Goyal N, Tsivgoulis G, Pandhi A, et al. Blood pressure levels post mechanical thrombectomy and outcomes in large vessel occlusion strokes. Neurology 2017;89:540-7.

6 Goyal N, Tsivgoulis G, Pandhi A, et al. Blood pressure levels post mechanical thrombectomy and outcomes in non-recanalized large vessel occlusion patients. $J$ Neurointerv Surg 2018;10:925-31.

7 Mistry EA, Mistry AM, Nakawah MO, et al. Systolic blood pressure within 24 hours after thrombectomy for acute ischemic stroke correlates with outcome. J Am Heart Assoc 2017:6:e006167.

8 Powers WJ, Derdeyn CP, Biller J, et al. 2015 American Heart Association/American Stroke Association Focused Update of the 2013 Guidelines for the early management of patients with acute ischemic stroke regarding endovascular treatment: a guideline for healthcare professionals from the American Heart Association/American Stroke Association. Stroke 2015;46:3020-35.

9 Wahlgren N, Moreira T, Michel P, et al. Mechanical thrombectomy in acute ischemic stroke: consensus statement by ESO-Karolinska Stroke Update 2014/2015, supported by ESO, ESMINT, ESNR and EAN. Int J Stroke 2016;11:134-47.

10 Powers WJ, Rabinstein AA, Ackerson T, et al. 2018 Guidelines for the Early Management of Patients With Acute Ischemic Stroke: A Guideline for Healthcare Professionals From the American Heart Association/American Stroke Association. Stroke 2018;49:e46-110.

11 Mistry EA, Mayer SA, Khatri P. Blood pressure management after mechanical thrombectomy for acute ischemic stroke: a survey of the strokenet sites. J Stroke Cerebrovasc Dis 2018:27:2474-8.

12 Higashida RT, Furlan AJ. Trial design and reporting standards for intra-arterial cerebral thrombolysis for acute ischemic stroke. Stroke 2003;34:109-37.

13 Wahlgren N, Ahmed N, Eriksson N, et al. Multivariable analysis of outcome predictors and adjustment of main outcome results to baseline data profile in randomized controlled trials: Safe Implementation of Thrombolysis in Stroke-MOnitoring STudy (SITS-MOST). Stroke 2008;39:3316-22.

14 Jauch EC, Saver JL, Adams HP, et al. Guidelines for the early management of patients with acute ischemic stroke: a guideline for healthcare professionals from the American Heart Association/American Stroke Association. Stroke 2013:44:870-947.

15 The European Stroke Organisation (ESO). Executive Committee and the ESO Writing Committee, Guidelines for Management of Ischaemic Stroke. 2008 https://eso-stroke. org/eso-guideline-directory/ (accessed 6 Jun 2018).

16 Goyal N, Tsivgoulis G, Iftikhar S, et al. Admission systolic blood pressure and outcomes in large vessel occlusion strokes treated with endovascular treatment. J Neurointerv Surg 2017:9:451-4.

17 de Havenon A, Bennett A, Stoddard GJ, et al. Determinants of the impact of blood pressure variability on neurological outcome after acute ischaemic stroke. Stroke Vasc Neurol 2017:2:1-6.

18 Bennett AE, Wilder MJ, McNally JS, et al. Increased blood pressure variability after endovascular thrombectomy for acute stroke is associated with worse clinical outcome. J Neurointerv Surg 2018;10:823-7.

19 John S, Hazaa W, Uchino K, et al. Timeline of blood pressure changes after intraarterial therapy for acute ischemic stroke based on recanalization status. J Neurointerv Surg 2017:9:455-8.

20 Manabe Y, Kono S, Tanaka T, et al. High blood pressure in acute ischemic stroke and clinical outcome. Neurol Int 2009;16:e1.

21 Maïer B, Gory B, Taylor G, et al. Mortality and disability according to baseline blood pressure in acute ischemic stroke patients treated by thrombectomy: a collaborative pooled analysis. J Am Heart Assoc 2017;6:e006484.

22 Schönenberger S, Uhlmann L, Ungerer M, et al. Association of blood pressure with short- and long-term functional outcome after stroke thrombectomy: post hoc analysis of the SIESTA Trial. Stroke 2018;49:1451-6. 